\title{
Effects of Intrathecal Bupivacaine and Bupivacaine Plus Fentanyl in Elderly Patients Undergoing Total Hip Arthroplasty
}

\author{
Huaxin Wang, Xuan Peng, Liying Zhan, Yeda Xiao and Bo Zhao \\ Department of Anesthesiology, Renmin Hospital of Wuhan University, Wuhan, Hubei, China
}

\begin{abstract}
Objective: To determine and compare the clinical efficacy of spinal anesthesia with bupivacaine combined with fentanyl and bupivacaine alone in geriatric patients scheduled for total hip arthroplasty (THA).

Study Design: Experimental study.

Place and Duration of Study: Department of Anesthesiology, Renmin Hospital of Wuhan University, Wuhan, Hubei, China, from April 2016 to April 2017.

Methodology: Sixty-five geriatric patients were randomised into two groups. Group B was anesthetised with $0.5 \%$ bupivacaine $10 \mathrm{mg}$ and Group F with $0.5 \%$ bupivacaine $7.5 \mathrm{mg}$ plus fentanyl $20 \mu \mathrm{g}$. Hemodynamic stability, effect and satisfaction of anesthesia, time to the first postoperative analgesic requirement, adverse effects, and incidence of postoperative indwelling catheter were compared.

Results: There was no significant difference in time to reach maximum sensory block level, maximum sensory block level, maximum motor block, duration of motor block, quality of anesthesia, adverse effects or the incidence of postoperative indwelling catheter between the two groups. However, Group $F$ required less dosage of ephedrine for stable hemodynamics and longer time to use the primary postoperative analgesic in comparison to Group $B(p<0.05)$.

Conclusion: Adding $20 \mu \mathrm{g}$ fentanyl to a lower dose of $7.5 \mathrm{mg}$ bupivacaine can provide safe and effective spinal anesthesia for THA in geriatric patients.
\end{abstract}

Key Words: Elderly, Total hip arthroplasty, Spinal anesthesia, Bupivacaine, Fentanyl.

How to cite this article: Wang $\mathrm{H}$, Peng $\mathrm{X}$, Zhan L, Xiao Y, Zhao B. Effects of intrathecal bupivacaine and bupivacaine plus fentanyl in elderly patients undergoing total hip arthroplasty. J Coll Physicians Surg Pak 2019; 29(12):1133-1137.

\section{INTRODUCTION}

Spinal anesthesia is a common anesthetic technique in total hip arthroplasty (THA). However, most patients who plan to have THA tend to be elderly, with cardiac, pulmonary or other diseases.1,2 Anesthesia has a large risk for complications, such as ischemia secondary to the hypotension, whereas THA must be performed urgently. The authors sought to identify a reliable spinal block by using a single-shot, low-dose technique for these patients with few side effects.

The objective of this study was to compare the effect and satisfaction of anesthesia, hemodynamic stability and side-effects in elderly patients scheduled for THA, who were grouped to receive spinal anesthesia either with bupivacaine $10 \mathrm{mg}$ or bupivacaine $7.5 \mathrm{mg}$ plus fentanyl $20 \mu \mathrm{g}$.

\section{METHODOLOGY}

This study was approved by the Hospital Ethics Committee of Renmin Hospital of Wuhan University,

Correspondence to: Bo Zhao, Department of Anesthesiology, Renmin Hospital of Wuhan University, Wuhan, Hubei, China

E-mail: zb14526@163.com

Received: March 11, 2019; Revised: October 08, 2019;

Accepted: October 19, 2019
China. Patients classified as American Society of Anesthesiologists I III undergoing elective THA signed informed consent, from April 2016 to April 2017. Exclusion criteria were age less than 65 years old, misunderstanding of oral information about the study, other severe systemic diseases, relative or absolute contraindications of spinal block, failure of block, or massive bleeding during the operation, surgery duration more than 90 minutes.

Patients were categorised into two study groups using a random number table method, which was prepared by an objective statistician, as follows: Group B were administered spinal anesthesia with $0.5 \%$ bupivacaine $10 \mathrm{mg}$ and Group $\mathrm{F}$ with $0.5 \%$ bupivacaine $7.5 \mathrm{mg}$ plus fentanyl $20 \mu \mathrm{g}$. If spinal anesthesia did not satisfy the surgery, we utilised general anesthesia for remedial measure, and these patients were excluded from the study.

The patients did not receive any sedation, analgesia or fluid infusion before arriving in the operating room. Fivelead electrocardiography, oxygen saturation, and noninvasive blood pressure monitoring were used. Before inducing spinal block, a 20-gauge intravenous cannula was inserted and compound sodium lactate solution 15 $\mathrm{ml} / \mathrm{kg} / \mathrm{h}$ was infused for approximately 30 minutes. An anesthesiologist, who was unaware of the clinical nature 
of the study, monitored and conducted the case. At the midline of L3-4 interspace in lateral position, lumbar puncture was performed. After observing the free flow of clear CSF, the scheduled drug was diluted to $3 \mathrm{~mL}$ with CSF and administered over 20-25 seconds with cephalad orientation. The patients were then immediately restored to supine position.

Pinprick testing was used to establish maximum sensory block level, and the time from subarachnoid injection drugs to reach highest level of sensory block was recorded. To judge maximum motor block scale, the modified Bromage score was used. The same team of orthopedic surgeons performed all operations after the anesthetist confirming adequate analgesia.

Heart rate (HR) and mean arterial pressure (MAP) were recorded at six time points (T0, baseline; T1, 5 minutes after spinal injection; T2, 15 minutes after spinal injection; T3, 30 minutes after spinal injection; T4, 45 minutes after spinal injection; T5, out of the post-anesthesia care unit). Hypotension was defined as a systolic arterial pressure below $90 \mathrm{~mm} \mathrm{Hg}$ or $20 \%$ below MAP baseline. If patients met either criterion, they were given ephedrine 3-10 mg intravenously, and the total dosage of ephedrine was recorded.

The quality of anesthesia during the operation was analysed as follows: 1 No discomfort or pain; 2 Mild pain or discomfort, whereas no requirement for additional analgesics; 3 Pain that needed analgesics; 4 Severe pain that needed analgesics. After the surgery, patients were taken to the post-anesthesia recovery room, hemodynamic parameters and the degree of analgesia were recorded until they were transferred to the surgical ward. During the operation and recovery, adverse effects, such as nausea, vomiting, shivering and pruritus were recorded.

Patients were transferred back to the surgical ward without indwelling catheters and early ambulation; and independent urination was encouraged. Indwelling catheters were inserted when the postoperative bladder filled with urine ( $>400 \mathrm{~mL}$ diagnosed by ultrasound) and could not be properly discharged. In case of visual analogue scale for postoperative pain was at least $4(0=$ no pain, $10=$ worst possible pain), intravenous flurbiprofen $(50 \mathrm{mg})$ was administered. The first time to give flurbiprofen is the time required for the first postoperative analgesia.The incidence of indwelling catheters and the time required for the first postoperative analgesia were recorded by an uninformed postoperative staff 24 hours after surgery.

Statistical analysis was performed using GraphPad Prism. Categorical variables were represented as count (\%); mean \pm standard deviation (SD) represented quantitative variables. Normality analysis was performed using Shapiro-Wilk normality test or Kolmogorov-Smirnov test with Dallal-Wilkinson-Lillie for $p$-value in GraphPad Prism software $(p>0.10$ indicate that the data was Gaussian distribution). The unpaired t-test, Mann-Whitney test, Fisher's exact test and Chi-square test were used for statistical analysis. Considered statistically significant were those $p$-values that were less than 0.05 .

\section{RESULTS}

In each group (Figure 1), there were 30 patients. Patients' characteristics were similar between the two groups

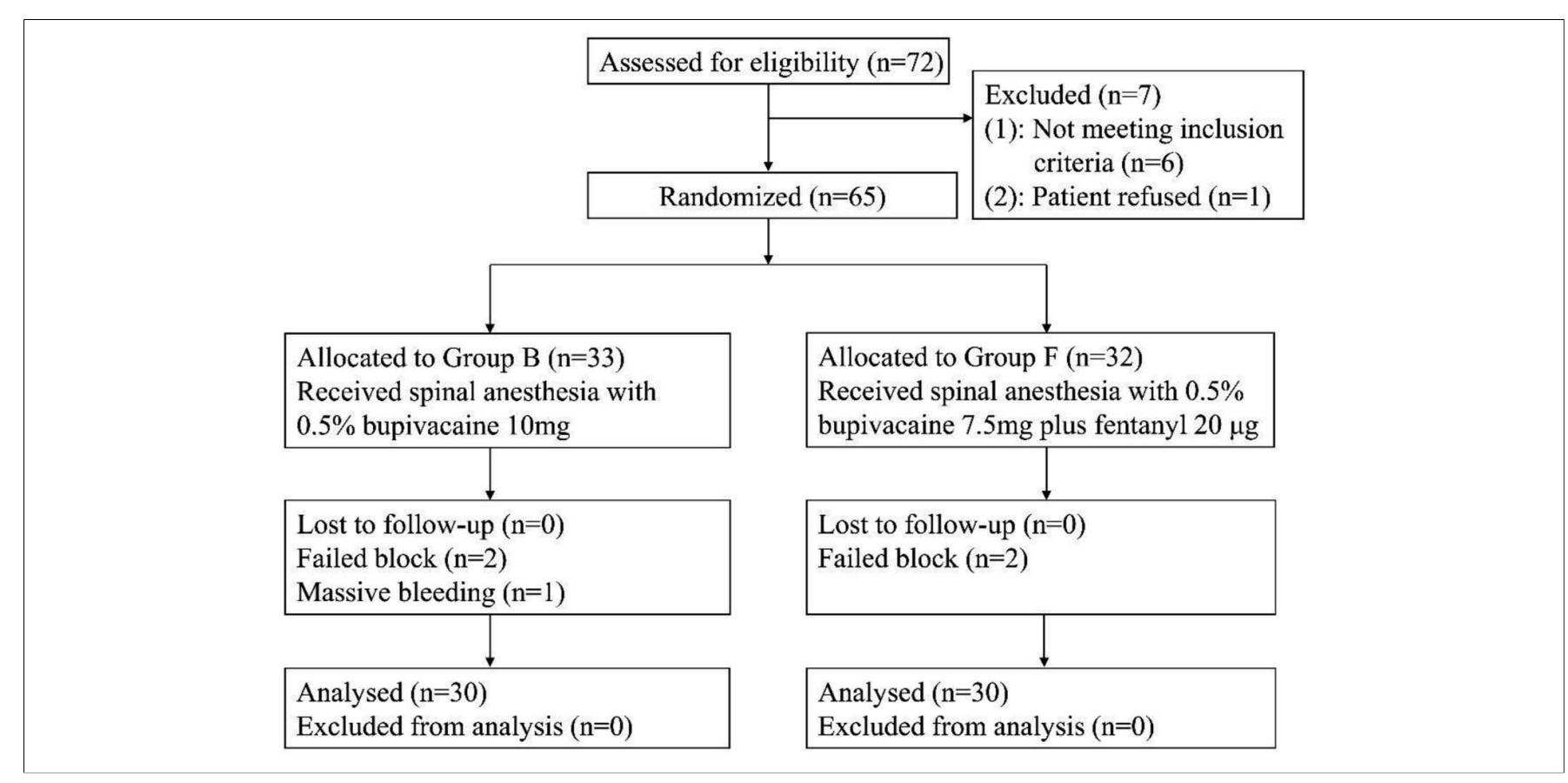

Figure 1: Flow diagram of patient recruitment. 

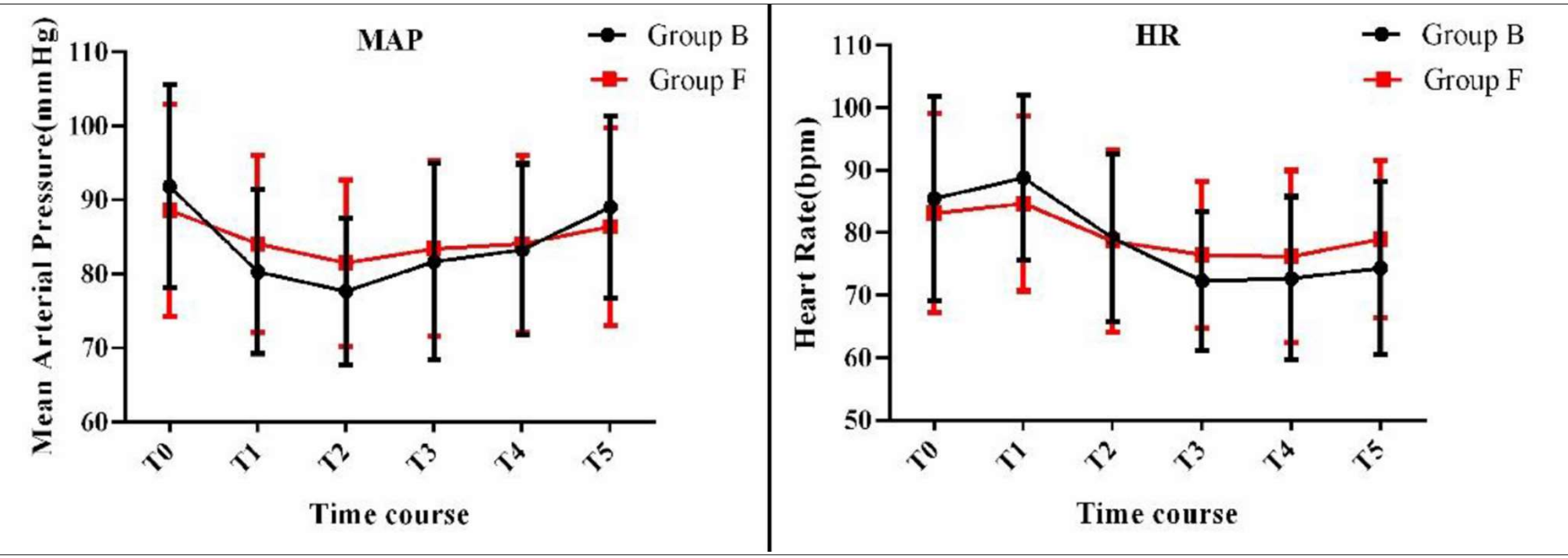

Figure 2: Hemodynamic variables at each recording time point. Values are shown as mean \pm SD. T0, baseline; T1, 5 min after spinal injection; T2, 15 min after spinal injection; T3, 30 min after spinal injection; T4, 45 min after spinal injection; T5, out of the post-anesthesia care unit.

Table I: Similar baseline characteristics in both groups.

\begin{tabular}{l|r|c|c}
\hline & $\begin{array}{c}\text { Group B } \\
(\mathrm{n}=30)\end{array}$ & $\begin{array}{c}\text { Group F } \\
(\mathrm{n}=30)\end{array}$ & -value \\
\hline Age (years) & $74.0 \pm 6.0$ & $75.2 \pm 5.8$ & 0.464 \\
\hline Gender & $27(90 \%)$ & $28(93.3 \%)$ & 1.000 \\
$\quad$ Male & $3(10 \%)$ & $2(6.7 \%)$ & \\
Female & $58.4 \pm 9.3$ & $61.1 \pm 9.6$ & 0.343 \\
\hline Weight $(\mathrm{kg})$ & $167.0 \pm 7.9$ & $168.1 \pm 8.5$ & 0.646 \\
\hline Height $(\mathrm{cm})$ & & & \\
\hline ASA & $3(10 \%)$ & $4(13.3 \%)$ & 0.811 \\
ASA I & $18(60 \%)$ & $19(63.3 \%)$ & \\
ASA II & $9(30 \%)$ & $7(23.3 \%)$ & \\
ASA III & $50.9 \pm 8.7$ & $49.0 \pm 8.0$ & 0.429 \\
\hline Duration of operation $(\mathrm{min})$ &
\end{tabular}

Data are shown as mean $\pm S D$ or number of patients, $S D=$ Standard deviation; $A S A=$ American Society of Anesthesiologists.

(Table I). There was no difference in MAP and HR at the corresponding time points between the two groups (Figure 2); however, Group F needed significantly less ephedrine than Group B (Table II).

There was no significant difference in the time to reach the highest level of sensory block, maximum sensory block level, maximum motor block, or quality of anesthesia between the two groups (Table II). Time to the first postoperative analgesic requirement in Group $F$ was longer than that in Group B. No difference was identified in adverse effects or the incidence of indwelling catheter postoperatively between the two groups (Table III).

\section{DISCUSSION}

In this study, administration of bupivacaine plus fentanyl spinal anesthetic ( $7.5 \mathrm{mg}$ bupivacaine plus $20 \mu \mathrm{g}$ fentanyl) for THA in elderly patients provided more effective anesthesia, required a lower dose of ephedrine for stable hemodynamics, and increased postoperative analgesic efficacy without increasing the incidence of adverse effects and postoperative indwelling catheters.
Table II: Characteristics of spinal anesthesia.

\begin{tabular}{|c|c|c|c|}
\hline & $\begin{array}{l}\text { Group B } \\
(\mathrm{n}=30)\end{array}$ & $\begin{array}{l}\text { Group F } \\
(n=30)\end{array}$ & p-value \\
\hline $\begin{array}{l}\text { Time to reach maximum } \\
\text { sensory block level (min) }\end{array}$ & $12.3 \pm 3.4$ & $13.6 \pm 4.0$ & 0.184 \\
\hline $\begin{array}{l}\text { Maximum sensory block level } \\
\text { T4 } \\
\text { T6 } \\
\text { T8 } \\
\text { T10 }\end{array}$ & $\begin{array}{c}2(6.7 \%) \\
8(26.7 \%) \\
16(53.3 \%) \\
4(13.3 \%)\end{array}$ & $\begin{array}{c}1(3.3 \%) \\
6(20 \%) \\
20(66.7 \%) \\
3(10 \%)\end{array}$ & 0.752 \\
\hline $\begin{array}{l}\text { Maximum motor block } \\
\text { Modified Bromage scale } 1 \\
\text { Modified Bromage scale } 2 \\
\text { Modified Bromage scale } 3 \\
\text { Modified Bromage scale } 4\end{array}$ & $\begin{array}{c}26(86.7 \%) \\
3(10 \%) \\
1(3.3 \%) \\
0(0 \%)\end{array}$ & $\begin{array}{c}24(80 \%) \\
5(16.7 \%) \\
1(3.3 \%) \\
0(0 \%)\end{array}$ & 0.588 \\
\hline Duration of motor block (min) & $183.7 \pm 31.5$ & $193.0 \pm 30.0$ & 0.200 \\
\hline $\begin{array}{l}\text { Time to the first analgesic } \\
\text { requirement }(\mathrm{h})\end{array}$ & $6.3 \pm 2.0$ & $7.8 \pm 2.5$ & $0.030^{*}$ \\
\hline $\begin{array}{l}\text { Quality of anesthesia } \\
\text { Quality of anesthesia } 1 \\
\text { Quality of anesthesia } 2 \\
\text { Quality of anesthesia } 3 \\
\text { Quality of anesthesia } 4\end{array}$ & $\begin{array}{c}27(90 \%) \\
2(6.7 \%) \\
1(3.3 \%) \\
0(0 \%)\end{array}$ & $\begin{array}{c}26(86.7 \%) \\
2(6.7 \%) \\
2(6.7 \%) \\
0(0 \%)\end{array}$ & 0.839 \\
\hline Total ephedrine (mg) & $11.8 \pm 7.8$ & $6.5 \pm 5.3$ & $0.005^{*}$ \\
\hline
\end{tabular}

Values are shown as mean $\pm S D$ or number of patients. Modified Bromage scale: 1, complete motor block; 2, medium block: difficulty raising legs; 3, minimal block: difficulty moving feet; 4 , no block. Quality of anesthesia was rated as follows: 1, no discomfort or pain; 2, mild pain or discomfort; no need for additional analgesics; 3 , pain that required analgesics; 4 , severe pain that required analgesics. *Indicates a significant difference at $p<0.05$.

Table III: Adverse effects and indwelling catheter postoperatively.

\begin{tabular}{l|c|c|c}
\hline & $\begin{array}{c}\text { Group B } \\
(\mathrm{n}=30)\end{array}$ & $\begin{array}{c}\text { Group F } \\
(\mathrm{n}=30)\end{array}$ & p-value \\
\hline Nausea & $2(6.7 \%)$ & $4(13.3 \%)$ & 0.389 \\
Vomiting & $1(3.3 \%)$ & $2(6.7 \%)$ & 0.554 \\
Pruritus & $0(0 \%)$ & $1(3.3 \%)$ & 0.313 \\
Shivering & $2(6.7 \%)$ & $1(3.3 \%)$ & 0.554 \\
Indwelling catheter & $5(16.0 \%)$ & $6(20.0 \%)$ & 0.739 \\
\hline
\end{tabular}

Values indicate the number of patients and percentage.

Elderly patients undergoing THA often have concurrent serious diseases, such as lung disease, coronary disease and brain ischemia disease. Spinal anesthesia 
can be used to low rates of perioperative adverse effects. ${ }^{3-5}$ However, unstable hemodynamics following spinal anesthesia is well known, and can be problematic for these patients. To maintain stable hemodynamics and reduce the potential complications due to hypotension during spinal anesthesia, general clinical practice is to decrease the dosage of local anesthetic, increase fluid infusion and use various adrenergic agonists; however, this approach increases the unacceptable anaesthetic failure rate and perioperative risks in elder patients. ${ }^{6-8}$ Moreover, it was demonstrated that both colloidal fluid and lactated Ringer's solution were safe for elderly patients undergoing total hip arthroplasty under spinal anesthesia. ${ }^{9}$ In this study, strategies aimed to maintain stable hemodynamics with compound sodium lactate solution preloading and with ephedrine were used.

Local anesthetics and opioids administered together intrathecally have a potent synergistic analgesic effect and can be potentially beneficial in critical patients. ${ }^{10-12}$ A few research reported that administration of low-dose bupivacaine with fentanyl could provide adequate anesthesia and recovery in patients scheduled for cesarean delivery or transurethral prostatectomy. ${ }^{13,14}$ Fentanyl is a lipid soluble synthetic opioid and has a small molecular weight and high potency. Intrathecal fentanyl can enhance sensory blockade without changing the degree of sympathetic blockade. 15 To the best of authors' knowledge, there was no published report on the administration of bupivacaine $(7.5 \mathrm{mg})$ plus fentanyl $(20 \mu \mathrm{g})$ in elderly patients undergoing THA.

In this study, both groups received the same quality of anesthesia; however, administration of bupivacaine with fentanyl required less ephedrine to maintain stable hemodynamics compared with single bupivacaine. Several studies demonstrated that the combination of intrathecal bupivacaine with fentanyl is effective in reducing impact on hemodynamics, 16,17 which is consistent with our findings. However, their drug formula was a mini-dose, with bupivacaine $(4 \mathrm{mg})$ plus fentanyl $(20 \mu \mathrm{g}$ or $25 \mu \mathrm{g}) .16,17$ These differences in doses may be due to the drug injection speed and drug density. In our study, using a combination of intrathecal bupivacaine plus fentanyl significantly increased time to first postoperative analgesic requirement. Farzi et al. and Gauchan et al. also showed that adjuvant fentanyl administration could significantly increase duration of analgesia compared with bupivacaine only. ${ }^{18,19}$

In our study, the incidence of adverse effects did not show any significant difference between the two groups. Lee et al. reported that the incidence of nausea and pruritus increased, while the incidence of shivering decreased after administering intrathecal fentanyl.20 These different results in adverse effects could have resulted from using different dosages of drug, the distinct types of surgery performed, and the variable ages of patients in the two studies.

Reducing indwelling catheter placements could help avoid related secondary urinary tract infection, ${ }^{21}$ especially in elderly patients. ${ }^{22}$ The authors previously showed that the incidence of postoperative indwelling catheter following administration of $3 \mathrm{~mL} 0.25 \%$ bupivacaine and $3 \mathrm{~mL} 0.375 \%$ bupivacaine for spinal anesthesia were $13.3 \%$ and $23.3 \%$, respectively. ${ }^{23}$ Moreover, additional fentanyl administration with intrathecal bupivacaine did not significantly increase the incidence of postoperative indwelling catheters. However, Fernandez et al. reported postoperative urinary retention only in $9 \%$ of male and $3 \%$ of female patients who underwent spinal anesthesia and intrathecal fentanyl. 24 This difference was likely due to the greater age and smaller sample size in this study.

\section{CONCLUSION}

Administration of $20 \mu \mathrm{g}$ fentanyl to intrathecal $7.5 \mathrm{mg}$ bupivacaine can provide safe and effective spinal anesthesia with no major adverse effects in elderly patients undergoing total hip arthroplasty.

This trial was registered at the Chinese Trial Registry. Registration number: ChiCTR-IOR-16007781. http://www. chictr.org.cn/showproj.aspx?proj=13084.

\section{ETHICAL APPROVAL:}

This study has been approved by the Hospital Ethics Committee of Renmin Hospital of Wuhan University prior to commencement of this research.

\section{PATIENTS' CONSENT:}

All patients signed informed consent for this study.

\section{CONFLICT OF INTEREST:}

Authors declared no conflict of interest.

\section{AUTHORS' CONTRIBUTION:}

Wang $\mathrm{H}$, Peng $\mathrm{X}$ : Made substantial contributions to the conception or design of the idea or the acquisition; drafted the work; revised it critically for important intellectual content. Zhan L: Analysed data, helped in writing the manuscript. Xiao Y: Participated in the design and coordination of the paper.

Zhao B: Participated in the design; final approval of the version to be published; agreement to be accountable for all aspects of the work.

\section{REFERENCES}

1. Singer A, Exuzides A, Spangler L, O'Malley C, Colby C, Johnston $\mathrm{K}$, et al. Burden of illness for osteoporotic fractures compared with other serious diseases among postmenopausal women in the United States. Mayo Clin Proc 2015; 90:53-62.

2. Lewiecki EM, Wright NC, Curtis JR, Siris E, Gagel RF, Saag KG, et al. Hip fracture trends in the United States, 2002 to 2015. Osteoporos Int 2018; 29:717-22. 
3. Liang C, Wei J, Cai X, Lin W, Fan Y, Yang F. Efficacy and safety of 3 different anesthesia techniques used in total hip arthroplasty. Med Sci Monit 2017; 23:3752-9.

4. Van Waesberghe J, Stevanovic A, Rossaint R, Coburn M. General vs. neuraxial anaesthesia in hip fracture patients: A systematic review and meta-analysis. BMC Anesthesiol 2017; 17:87.

5. Meuret P, Bouvet L, Villet B, Hafez M, Allaouchiche B, Boselli E. Hypobaric unilateral spinal anaesthesia versus general anaesthesia in elderly patients undergoing hip fracture surgical repair: A prospective randomised open trial. Turk $J$ Anaesthesiol Reanim 2018; 46:121-30.

6. Lemoine A, Mazoit JX, Bonnet F. Modelling of the optimal bupivacaine dose for spinal anaesthesia in ambulatory surgery based on data from systematic review. Eur $\mathrm{J}$ Anaesthesiol 2016; 33:846-52.

7. Dizman S, Turker G, Gurbet A, Mogol EB, Turkcan S, Karakuzu Z. Comparison of two different doses of intrathecal levobupivacaine for transurethral endoscopic surgery. Eurasian $\mathrm{J}$ Med 2011; 43:103-8.

8. Neuman MD, Rosenbaum PR, Ludwig JM, Zubizarreta JR, Silber $\mathrm{JH}$. Anesthesia technique, mortality, and length of stay after hip fracture surgery. JAMA 2014; 311:2508-17.

9. Zhang Y, Yu Y, Jia J, Yu W, Xu R, Geng L, et al. Administration of HES in elderly patients undergoing hip arthroplasty under spinal anesthesia is not associated with an increase in renal injury. BMC Anesthesiol 2017; 17:29.

10. Vedagiri Sai R, Singh SI, Qasem F, Nguyen D, Dhir S, Marmai K, et al. Onset of labour epidural analgesia with low-dose bupivacaine and different doses of fentanyl. Anaesthesia 2017; 72:1371-8.

11. Dourado AD, Lins Filho RL, Fernandes RA, de Sá Gondim MC, Nogueira EV. Sufentanil in combination with low-dose hyperbaric bupivacaine in spinal anesthesia for cesarean section: A randomized clinical trial. Rev Bras Anestesiol 2016; 66:622-7.

12. Sanatkar M, Farhanchi A, Manouchehrian N, Najafi A, Haddadi S, Rahmati J. Subarachnoid block with low dose of bupivacaine and sufentanil in patients with coronary artery disease. ARYA Atheroscler 2014; 10:94-9.

13. Rasooli S, Moslemi F, Parish M, Mahmoodpoor A, Sanaie S. Spinal anesthesia with minidose bupivacaine-fentanyl for cesarean section in preeclamptic parturients. Saudi Med J 2008; 29:460-2.

14. Kim SY, Cho JE, Hong JY, Koo BN, Kim JM, Kil HK. Comparison of intrathecal fentanyl and sufentanil in low-dose dilute bupi- vacaine spinal anaesthesia for transurethral prostatec-tomy. $\mathrm{Br}$ J Anaesth 2009; 103: 750-4.

15. Ngan Kee WD, Khaw KS, Ng FF, Ng KK, So R, Lee A. Synergistic interaction between fentanyl and bupivacaine given intrathecally for labor analgesia. Anesthesiology 2014; 120:1126-36.

16. Ben-David B, Frankel R, Arzumonov T, Marchevsky Y, Volpin G. Minidose bupivacaine-fentanyl spinal anesthesia for surgical repair of hip fracture in the aged. Anesthesiology 2000; 92: 6-10.

17. Akcaboy ZN, Akcaboy EY, Mutlu NM, Serger N, Aksu C, Gogus N. Spinal anesthesia with low-dose bupivacaine-fentanyl combination: A good alternative for day case transurethral resection of prostrate surgery in geriatric patients. Rev Bras Anestesiol 2012; 62:753-61.

18. Farzi F, Mirmansouri A, Naderi Nabi B, Atrkar Roushan Z, Ghazanfar Tehran S, Nematollahi Sani M, et al. Comparing the effect of adding fentanyl, sufentanil, and placebo with intrathecal bupivacaine on duration of analgesia and complications of spinal anesthesia in patients undergoing cesarean section. Anesth Pain Med 2017; 7:e12738.

19. Gauchan S, Thapa C, Prasai A, Pyakurel K, Joshi I, Tulachan J. Effects of intrathecal fentanyl as an adjunct to hyperbaric bupivacaine in spinal anesthesia for elective caesarean section. Nepal Med Coll J 2014; 16:5-8.

20. Lee JH, Chung KH, Lee JY, Chun DH, Yang HJ, Ko TK, et al. Comparison of fentanyl and sufentanil added to $0.5 \%$ hyperbaric bupivacaine for spinal anesthesia in patients under-going cesarean section. Korean J Anesthesiol 2011; 60:103-8.

21. Tomaszewski D, Balkota M. Intramuscular administration of drotaverine hydrochloride decreases both incidence of urinary retention and time to micturition in orthopedic patients under spinal anesthesia: A single blinded randomized study. Biomed Res Int 2015; 2015:926953.

22. Campbell L, Sammon J, Rahbar H, Patel S, Wolfe-Christensen C, Kabbani L, et al. Postoperative urinary retention in men is common after carotid endarterectomy and is associated with advanced age and prior urinary tract infection. $J$ Vasc Surg 2016; 63:355-61.

23. Gao W, He Z, Zhao B, Tang C, Xiao Y, Jiang M, et al. Different concentrations of bupivacaine on postoperative urinary retention in patients undergoing subarachnoid anesthesia. Int J Clin Exp Med 2017; 10:10840-5.

24. Fernandez MA, Karthikeyan S, Wyse M, Foguet P. The incidence of postoperative urinary retention in patients undergoing elective hip and knee arthroplasty. Ann R Coll Surg Engl 2014; 96:462-5 